\title{
Translating the Earth: Practices, Tools, and Credibility in Eighteenth Century Cave Surveys
}

\author{
Johannes Mattes \\ Austrian Academy of Sciences, Vordere Zollamtsstraße 3, 1030 Vienna, Austria, johannes.mattes@oeaw.ac.at
}

Keywords: Cave Maps, Enlightenment, Scientific Practises, Tools, Trust

\begin{abstract}
:
This paper deals with natural cavities and the practices, tools, and mechanisms of trust involved in their survey and visualization in map format. Caves, like other subterranean and vertical sites of scientific inquiry (mines, mountains), were the focus of a wide range of scholarly approaches in this period. Practitioners from different areas brought a great diversity of methodologies and means of translation to their work in the emerging field of cave studies. Striking observational results, untrustworthy visitor reports, and findings that furnished evidence of geological or "deep-time" processes all intensified this scientific interest. However, demanding conditions underground - such as remoteness, limited vision, and topography that was difficult to navigate-posed a considerable challenge for early modern experience-based knowledge acquisition, casting empirical methods of observing, measuring, and recording into doubt.
\end{abstract}

Relating on-site observations with the modes of cartographic representation, the paper investigates the transformation of knowledge from the measuring tape to the drawing table and the process of ascribing credibility to these materialized visions of earth. Faced with the challenge of limited vision underground, mapmakers combined empiricism and imagination in an experimental setting and developed specific translation strategies to deal with the shifting boundaries between known and unknown and the hybridity of objects found in caves.

By sketching the outlines of the changing epistemic function of maps, this paper provides new insights into the processes by which visualizations of underground space became devices in Enlightenment scientific reasoning, all while surveyors struggled with the inexact nature of visual observation. Preserved in archive and printed sources, cave surveys made in Europe and drawn by scholars such as Nicolas Brémontier (1738-1809), Georg Buchholtz (1688-1733), or Eggert Ólafsson (1726-1768) form the basis of this study. 